\title{
Edge Models with the CAD Software: Creating a New Context for Mathematics in Elementary School
}

\author{
Felicitas Pielsticker ${ }^{1}$ (D) $\cdot$ Ingo Witzke $^{1} \cdot{\text { Amelie } \text { Vogler }^{1} \text { (iD }}^{-}$
}

Accepted: 8 June 2021 / Published online: 12 July 2021

(C) The Author(s) 2021

\begin{abstract}
Digital media have become increasingly important in recent years and can offer new possibilities for mathematics education in elementary schools. From our point of view, geometry and geometric objects seem to be suitable for the use of computeraided design software in mathematics classes. Based on the example of Tinkercad, the use of CAD software - a new and challenging context in elementary schools - is discussed within the approach of domains of subjective experience and the Toulmin model. An empirical study examined the influence of Tinkercad on fourthgraders' development of a model of a geometric solid and related reasoning processes in mathematics classes.
\end{abstract}

Keywords Reasoning processes in mathematics classes $\cdot$ Digital media $\cdot$ Solid geometry $\cdot$ Elementary school $\cdot$ CAD software

This article examines an example taken from a study conducted in a German elementary school showing how children develop a model of a geometric solid using specific, self-designed, digital objects in the computer-aided design (CAD) software Tinkercad. Within a learning environment designed for this study focusing on developing the concept of the "cube," we discuss the extent to which student knowledge transfer is initiated in settings using digital media in elementary school mathematics. We argue that the exploratory use of self-created program objects challenges student knowledge and influences student learning, and use the descriptive approach of the domains of subjective experience (DSEs) (Bauersfeld, 1983) and the Toulmin model (Toulmin, 1958/1996) to describe the exploratory processes in detail.

Amelie Vogler

vogler2@mathematik.uni-siegen.de

Felicitas Pielsticker

pielsticker@mathematik.uni-siegen.de

Ingo Witzke

witzke@mathematik.uni-siegen.de

1 Mathematics Education, University of Siegen, Siegen, Germany 


\section{CAD Software: A Potential for Mathematics Education}

Before we analyze the collected data, the software the students used is presented. Tinkercad is a web-based, free-to-use CAD program by Autodesk (2020) "[...] that helps people all over the world think, create, and make." Compared with other such programs, Tinkercad inherits a particularly intuitive approach of modeling three-dimensional (3D) objects directly, providing easy access to such software for first-time users, such as elementary school students. As several research projects have already shown (Dilling \& Vogler, 2021; Dilling \& Witzke, 2020a, b; Gibson et al., 2014; Pielsticker, 2021; Pielsticker \& Witzke, 2022; Ng, 2017; $\mathrm{Ng} \&$ Sinclair, 2018; $\mathrm{Ng}$ et al., 2018), this program affords students of all ages a good start in 3D printing technology.

Recent research indicates how 3D printing technology can be implemented in mathematics classes in (upper) secondary school, for example, to explore central concepts of calculus (Dilling \& Witzke, 2020a). Furthermore, Dilling and Witzke (2020b) describe how primary students use 3D printing technology, combined with the CAD program SketchUp, in a learning unit about tessellation in geometry lessons and state that digital media could raise various challenges (i.e., virtual enactivity and technical problems), in addition to different advantages, such as precision (p. 90).

Another recent case study by Dilling and Vogler (2021) provides insight into the possibilities of fostering spatial ability through such software in secondary school. In the study by $\mathrm{Ng}$ (2017), the CAD software and 3D printing are used for teaching about the volume of solids in junior secondary mathematics classrooms. The work by $\mathrm{Ng}$ and colleagues (2018) highlights the potential of "doing, thinking, and learning mathematics with the emergence of technological innovation that enables real-time 3D virtual and material interactions" (p. 563), while $\mathrm{Ng}$ and Sinclair (2018) conclude that, "3D Drawing Pens provided important insights on the affordances of a 3D drawing environment for mathematics learning" ( $p$. 312).

A case study by Pielsticker (2021) provides insight into how 3D printing technology can be used to support eighth-grade learners' concept formation processes in geometry lessons when calculating the area of triangles. This related research on implementing 3D printing technology in mathematics classes highlights some of the specificities and challenges concerning the student learning process. We expand this field of research with this case study by providing deeper insight into the influence of using CAD software in geometry classes in elementary school. In particular, this study is designed to investigate the primary students' reasoning process while using this program, which is essential if students are supposed to develop objects to be printed during class.

$\mathrm{Ng}$ and Sinclair (2018) noted that the actions and gestures of the students play a decisive role during the $3 \mathrm{D}$ drawing process with a $3 \mathrm{D}$ pen. The same applies to our article, in which we consider actions and objects to be decisive for the description of several contexts, which emerged in the learning setting using the DSE approach (Bauersfeld, 1988). In our case study, objects and the actions 


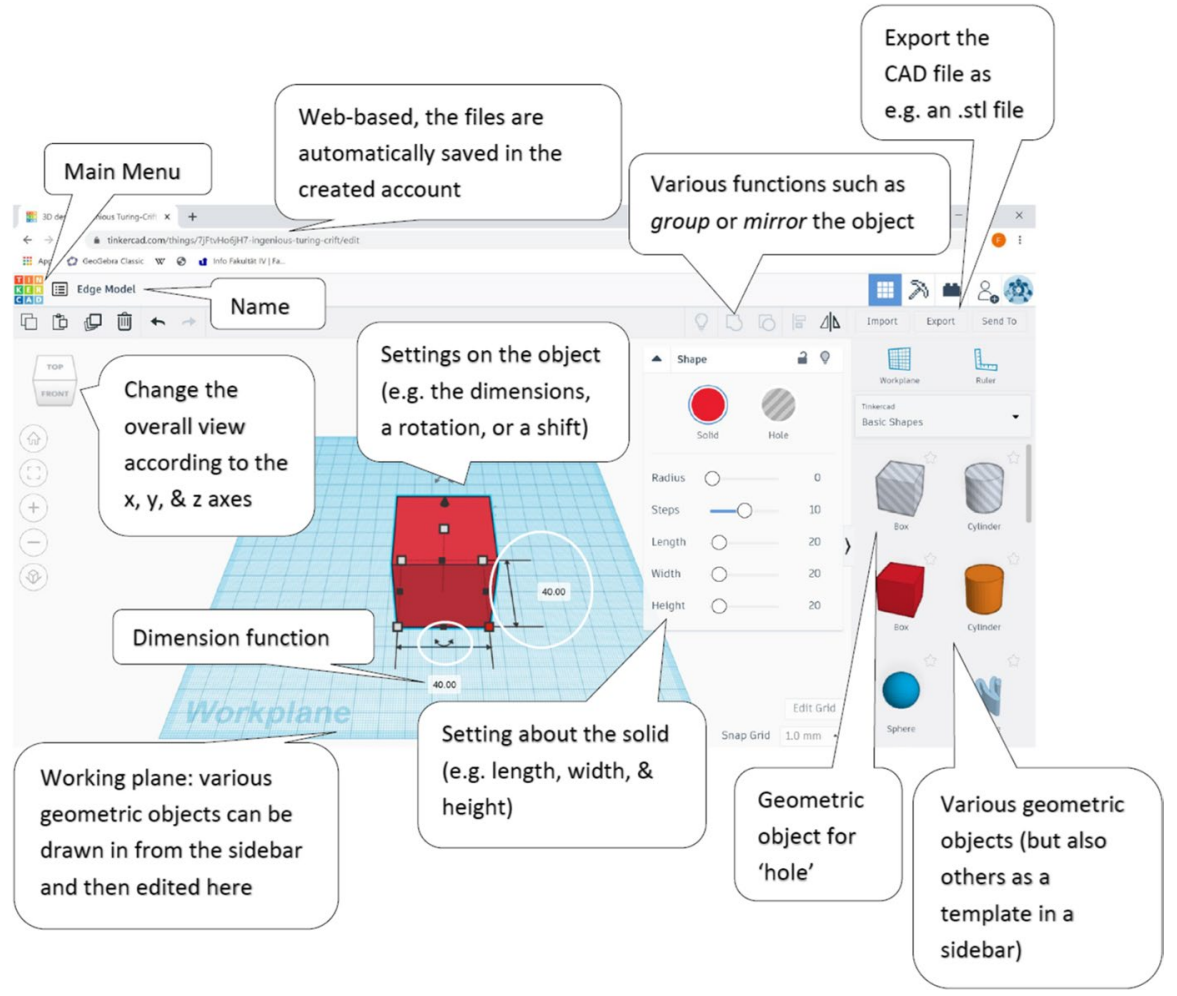

Fig. 1 Interface of the CAD program Tinkercad

and gestures carried out on them influenced the student reasoning processes, especially while developing a cube model using the CAD software Tinkercad. Figure 1 presents a short description of the functions available in the program interface.

In addition, it is important to know several operations that can be conducted with virtual objects in the program that distinguish it from the "analog" world and the related operations that can be done with physical objects (see Figs. 2, 3, and 4).
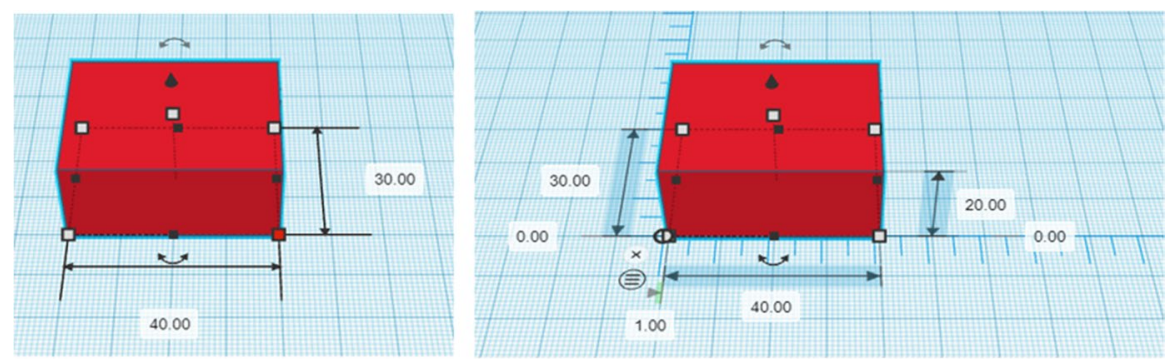

Fig. 2 Operation to scale an object in Tinkercad (on the right with the ruler and on the left without) 

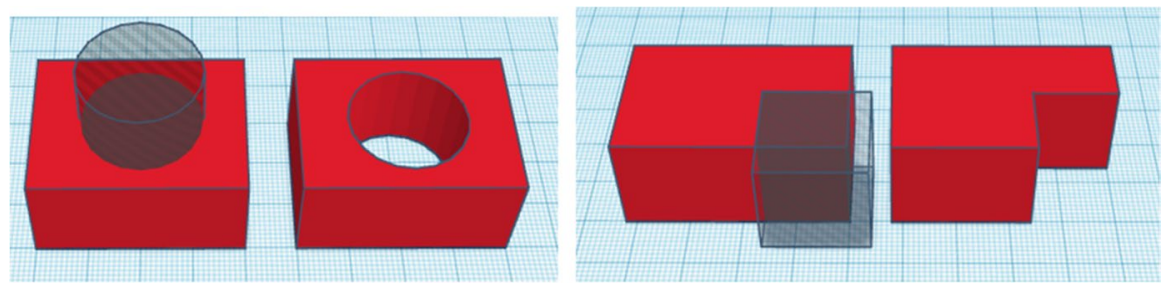

Fig. 3 Operation to drill a hole in an object and to reduce an object by another object in Tinkercad

As illustrated in Fig. 2, an object can be scaled by pulling the corners with the cursor or entering specific measurements. A ruler can also be placed at any desired position. Figure 3 presents how one can drill a hole in an object or reduce an object by using another - in this case, a cylinder or cube. Every object on the work plane can be transformed into a hole with one click. In Fig. 4, the operation to group several objects is exemplified with a cube and roof. These are some of the functions, among many others, that the program offers.

According to the widely discussed SAMR model (Puentedura, 2013), we view the implementation of CAD software for developing (geometric) models as an augmentation and, partly, as a modification of traditional mathematics classes. The program allows completely new actions on objects (e.g., duplicating, cutting and drilling, placing inside each other) and adds another level of representation to the students, namely, the virtual-enactive level (concerning representation levels, see Bruner, 1974, and concerning computer science education, see Hartmann et al., 2007). At this level of representation, virtual concrete objects, such as geometric ones, can be handled on the virtual work plane of the program by students in a completely new way compared with the actions of physical objects in the analog world.

Fig. 4 Operation to group several objects in Tinkercad

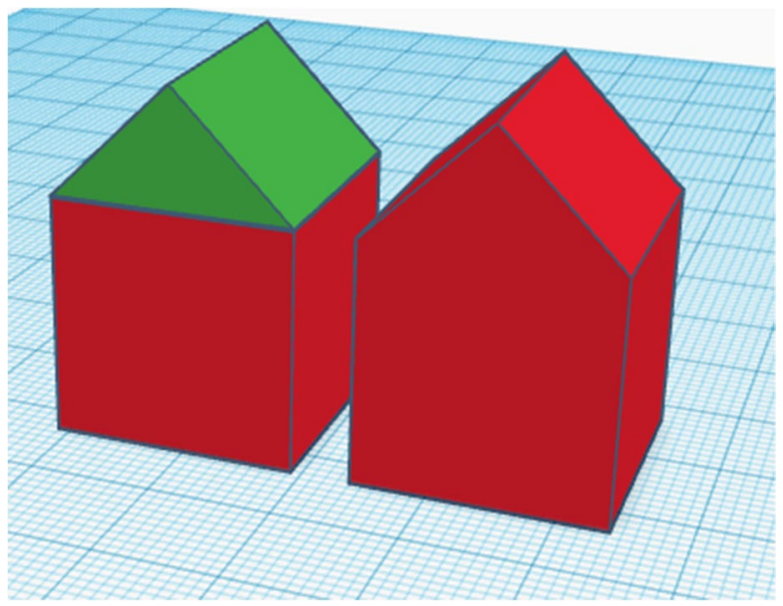




\section{Method: Descriptive Perspective}

The data collection was conducted by videotaping different phases of teaching and learning, which are described in the third sub-section below (setting and participants). In addition, we took screen recordings of the program's interface when the students worked with the CAD program. The video material and screen recordings were transcribed following the method by Meyer (2010). In addition to the transcripts of the teaching and learning situations, student documents (in the form of constructions using Tinkercad) were also part of our investigation. We use a descriptive perspective to analyze the specifics in the student interactions while dealing with the program and the specifics in the observed student reasoning processes. Therefore, we use two theoretical concepts, which are described in the first two sub-sections. Then, in the final sub-section, we explain our research questions and related theoretical assumptions.

\section{Domains of Subjective Experience}

To describe ideas about specific objects developed by students using 3D printing technology, we use the concept of domains of subjective experience (DSEs) by Bauersfeld (1983). The concept allows us to describe how students develop their knowledge in a constructivist and interactionist sense. The core idea is that learning is a domain-specific process and can be described as bound to a specific situation and context. The domains include the meaning, language, objects, and actions encompassing cognitive and motivational or emotional dimensions. In this article, we focus on the cognitive dimension with respect to elementary school children. According to Bauersfeld (1988):

"[...] learning is characterized by the subjective reconstruction of social means and models through the negotiation of meaning in social interaction and in the course of related personal activities. New knowledge, then, is constituted and arises in the social interaction of members of a social group (culture), whose accomplishments reproduce as well as transmute the culture. (p. 39)"

Language plays a particularly important role in linking separate DSEs. We assume that a term has a meaning, especially in connection with other terms, but each one has specific language use (Tiedemann, 2016). A generalization of terms is primarily achieved by managing a cognitive conflict, so that an analogy can be formed and common mathematical content from two different DSEs can be recognized. This process requires a newly formed DSE that enables the analogy to be recognized through a spontaneous, interactive constitution of meaning by the learner (Bauersfeld, 1983). Against this background, the formation of connections between mathematical structures does not appear to be trivial for developing mathematical concepts. To make sense of mathematical contexts, negotiating terms plays a crucial role in interaction with other learners (Bauersfeld, 2000). 


\section{Argument (Data)}

Thesis (Conclusion)
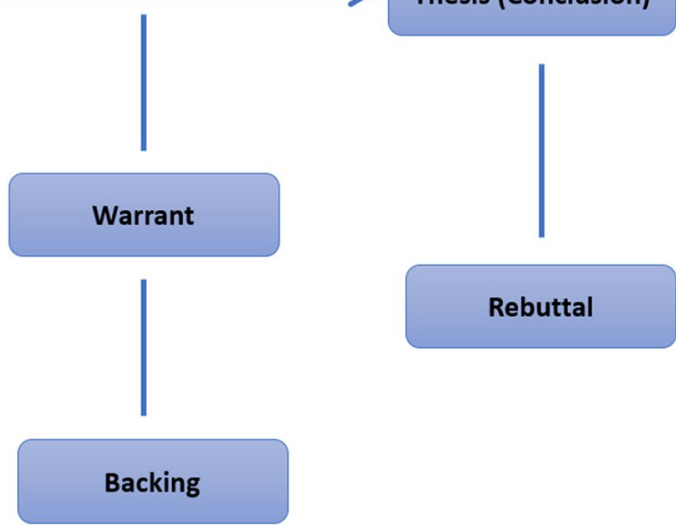

Rebuttal

Fig. 5 The Toulmin model

Additionally, in some learning situations, concrete advice by the teacher is needed that causes a cognitive conflict and requires the student to form a new DSE.

With the help of DSEs, we describe and analyze the knowledge development processes for creating a model of a geometric solid with the CAD software. The concrete learning environment is described in the fourth sub-section. Dilling and Witzke (2020a) stated, "the descriptions of the [...] empirical objects [...] the virtual 3D-models and the 3D-printed models, [...] [are] objects of reference [that] constituted the [DSEs]" (p. 337). The actions and terms used on the empirical objects also play a decisive role. Therefore, the focus is on empirical objects and the language and terms used by the students, because, "[we] have not only to analyze objects that we use in mathematics classes, but we have to analyze children's associations with them, too" (Fetzer \& Tiedemann, 2018, p. 1290).

\section{The Toulmin model}

As a key descriptive method for analyzing specifics in the observed student reasoning processes, we use the analytical model named after Stephen Toulmin, which is well known in mathematics education (Krummheuer, 2003; Loui, 2006). Figure 5 depicts the general structure and main terms of this model.

In the Toulmin model (Toulmin, 1958/1996), a thesis that needs to be explained (conclusion) is supported by arguments (or data). The reasoning rule (warrant) can be supported by certain facts or arguments (backing). According to Toulmin, warrants are hypothetical propositions building a bridge between the argument and conclusion. It is interesting that, in contrast to arguments, warrants are usually expressed only implicitly. Furthermore, the backing supports the warrants to avoid possible antitheses and contestations of the arguments or data. In general, various types of backing are available as follows: laws, standards, regulations, principles, general facts, recognized provisions, recognized experience, needs, and classifications. The 
Toulmin scheme helps to describe or reconstruct a reasoning process precisely in its structure but does not judge its coherence.

\section{Setting and Participants}

In this study, we describe the knowledge development processes of elementary school students when constructing edge models using digital media in geometry at the beginning of the fourth year in a German public school. We decided on a kit for an edge model, because the individual components can be easily created. It is possible to put the 3D-printed objects together after the printing process. If an edge model was printed directly as a whole, more support and material would be required in the printing process (e.g., the use of support material). The 25 students spent two mornings dealing with the topic of cubes. They were instructed to create a kit for an edge model of a cube using 3D printing technology. The teaching and learning setting was organized into these five phases: (1) introducing the learning context and understanding the task instructions; (2) planning how to build and construct the kit with the Tinkercad in groups of two students; (3) developing the kit for an edge model of a cube in the program; (4) 3D printing and assembling the kit; (5) reflecting on the work process and presenting individual results and reflections. Phases 1 to 3 were selected for this study and are described in more detail below.

The students were familiar with 3D representations of geometric objects from previous mathematics lessons. As we knew when planning the unit, they had already examined and prepared construction plans for edge models and cube nets in class. Implementing a CAD program, which was necessary to construct and print the $3 \mathrm{D}$ edge models, was designed to help analyze how students at the elementary school level handle digital contexts. Moreover, we wanted to gain insight into the process of how students transfer their knowledge constructed in their physical (analog) world to the virtual (digital) world, in this example, elementary geometry.

We intended to activate already-consolidated and available knowledge about geometric objects during the introduction phase, by placing different empirical objects ${ }^{1}$ resembling different familiar geometric objects in the middle of a "seat circle" in the classroom (see Fig. 6). The students were asked to arrange and sort these objects, following their own paths. After the students sorted the objects, the class discussed their sorting criteria. It was repeated that corners, edges, and surfaces are valuable for sorting geometric objects into different classes. The students exhibited "adequate behavior" in the mathematics classroom and classified the objects according to geometric properties, such as the shape or quantity of the edges, corners, and sides.

The next step was to determine what a kit for an edge model of a cube should include, which properties should be met and which criteria are decisive. The teacher decided that the edge model should be created using cubes as cornerstones and cylinders as edges. For this purpose, three recesses had to be constructed in each

\footnotetext{
1 According to Pielsticker (2020, p. 40), empirical objects are understood as items and objects of reality that are immediately accessible to students, especially in a tactile or visual way. In this study, these include all objects developed and produced with 3D printing technology.
} 


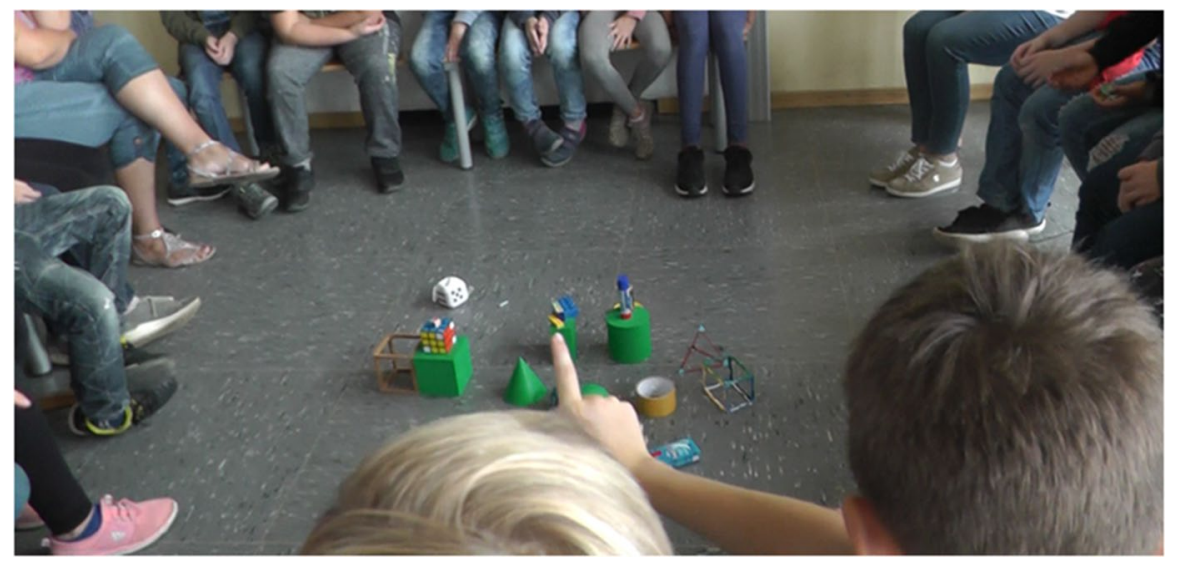

Fig. 6 Seat circle with geometric objects in the middle

cornerstone in the program. Then, the quantitative, classical, short profile of a cube was repeated and written on the board (Fig. 7). This ties in with the German standards in mathematical education. In the area referring to space and shape, the standards state:

Sort solids and plane figures by properties and assign terms (like "cube") recognize solids and plane figures in the environment, create, and explore models of solids and plane figures (building, placing, disassembling, assembling, cutting, folding...) (Kultusministerkonferenz (KMK), 2005, p.10; authors' translation).

Then, the second phase, namely, planning how to build and construct the kit using Tinkercad, was initiated. In conversation, the students considered how an edge model could be created with 3D printing technology. In the local curriculum, exploring geometric solids is required from the beginning of elementary school. In the first and second grades, students build models of solids (e.g., from plasticine)

Fig. 7 Profile of a cube (In this article, we stay with "corners" and "sides" at a more informal level of description. In German mathematics lessons, this problem of terminology ("corners" or "vertices") does not arise because the term used is Ecke.)

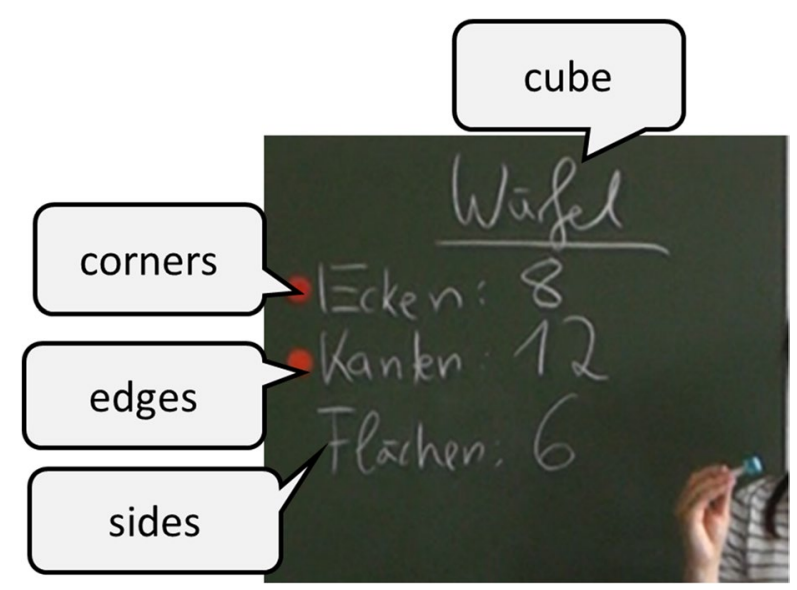


and create and consider buildings made of several cubes. As stated for third and fourth grades, students should create edge models of solids (Lehrplan 2008). The teaching and learning setting in question is about creating an edge model of a cube using 3D printing technology (with Tinkercad as the software component) and was originally designed to strengthen student knowledge on geometric solids.

To gain data related to the research questions (see immediately below), we did not examine the class as a whole, but instead single students or pairs of students who demonstrated conspicuities in their working procedures. These conspicuities can be (cognitive) difficulties in fulfilling the task or unexpected usages of the program.

\section{Research Questions and Related Theoretical Assumptions}

The research questions are as follows:

RQ 1: What influence does the CAD software Tinkercad have on student reasoning processes in mathematical learning settings?

RQ 2: What are the characteristics of the implementation of this new context in mathematics classes?

Regarding the term reasoning processes in the first research question (RQ 1), we do not refer to mathematical reasoning, but rather to a general process of how students develop a thesis that can be analyzed using the Toulmin model. In Germany, both in elementary and in secondary schools, the standards for mathematics education require a focus on general process-oriented abilities, such as problem-solving, communicating, (re)presenting, modeling, and reasoning. The ability to reason includes questioning and checking the correctness of mathematical statements, recognizing mathematical relationships and developing (mathematical) assumptions, and searching for and understanding reasons (KMK, 2005, p. 8; authors' translation).

Therefore, we are interested in the influence of this CAD software on the student reasoning processes. As explained in the previous section, we consider the software implementation a new context in mathematics classes with a high potential for learning environments, including geometric aspects. Nevertheless, examining the characteristics of implementing this new context is important because of the multiple possibilities the software offers concerning the new level of representation. In our second research question (RQ 2), we ask about these characteristics.

Related to RQ 1, we assume that students transfer their (mathematical) knowledge about geometric solids and measuring processes that they have constituted in the previous lessons to the digital context of the CAD software. In particular, we expect that using the program's specific functions (e.g., scaling and measuring with the ruler) during the development of the kit for the edge model strengthens the students' knowledge and skills in the measuring area. Regarding RQ 2, we assume that the students in our setting will use the specific functions and associated operations offered by the program. We use the concept of DSEs to analyze the actions and language the students used as they developed an edge model, and to describe how their 
Table 1 Transcript excerpt from the planning phase

\begin{tabular}{llll}
\hline 249 & Teacher: & $\# 00: 21: 20-4 \#$ & What do we need to build the kit of an edge model of a cube? \\
\hline$[\ldots]$ & & & \\
260 & Teacher: & $\# 00: 22: 34-3 \#$ & $\ldots$ Klarissa? \\
261 & Klarissa: & $\# 00: 22: 41-8 \#$ & Ehm, twelve sticks \\
262 & Teacher: & $\# 00: 22: 43-5 \#$ & Exactly \\
263 & Klarissa: & $\# 00: 22: 43-5 \#$ & And eight little cubes (in German:Würfelchen) \\
264 & Teacher: & $\# 00: 22: 46-5 \#$ & $\begin{array}{l}\text { Exactly. You've done this gesture already (holds both hands } \\
\text { together, moves them up and down in opposite directions) }\end{array}$ \\
& & & $\ldots$ Luna? \\
265 & Luna: & $\# 00: 22: 51-7 \#$ & Ehm ... and the sticks must fit exactly into the little cubes \\
\hline
\end{tabular}

knowledge, which was activated in several phases of the process, was bound to specific contexts and then to characterize these contexts.

\section{Findings}

\section{Data Descripition}

We describe and analyze selected transcript excerpts, focusing on a transfer of knowledge from a 3D printed edge model kit to a virtual one in the CAD environment of the program Tinkercad. After a first review of the data, we immediately noticed the two girls, Klarissa and Luna (pseudonyms), because they used diminutives of specific terms (i.e., "Würfelchen" instead of cube/Würfeland "Stäbchen" instead of stick/stab or cylinder") in Phases 1 and 2, when in Phase 3 (working with the software), they switched to the terms "edges" and "corners." After further review, we also noticed they were striving for precision in their actions on the work plane in the program.

In the first situation (Table 1), the teacher spoke to the whole class (Phase 1). In the following discussion, properties were collected to construct successfully the kit for an edge model (Fig. 8) with the software. All students were sitting in the seat circle with various geometric objects available, varying in material and shape (Fig. 6), including 3D-printed objects. Regarding the background to the following transcript, it is already clear that 3D printing should be used. The excerpts are from the second day of investigation, and the students had already worked with the program on the previous day. Klarissa articulated that "twelve sticks" and "eight little cubes" (Table 1, turns 261 and 263) are needed. Luna's gesture indicates "sticking together" and "fitting into one another" and she said, "the sticks must fit exactly into the little cubes" (Table 1, turn 265).

\footnotetext{
${ }^{2}$ In German, the suffixes "-chen" and "-lein" are often used to build the diminutive of a word.
} 

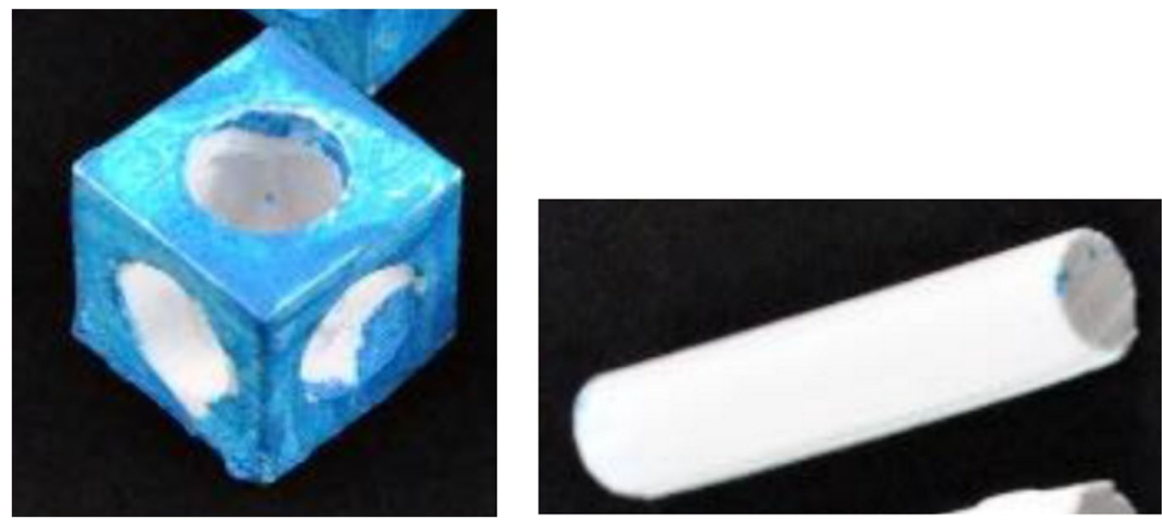

Fig. 8 Three-dimensional printed objects for the kit of an edge model of a cube

The following transcript excerpts (Tables 2, 3, and 4) are taken from the teamwork phases of the students designing virtual edge models (suitable for 3D printing) after the whole classroom session (Phases 2 and 3). While the students were in a classroom for the whole classroom discussion, with children seated around in a circle at first, they switched to a computer room to work with the software. In the following transcript (Table 2), Klarissa and Luna focused on it. After a short familiarization with the program, they started constructing their kits for the edge model. Klarissa and Luna had already created some of the "little cubes," the cornerstones of their model, and considered how many corners were still missing for their model and counted those already created in the program. They noted that the edges also needed to be created (Table 2, turn 70).

In the following transcript (Table 3), Klarissa and Luna raised the question of how the edges of their model could be created and what needed to be considered. As seen above, they already knew that the edges must fit in the corners. The following transcript (Table 4) demonstrates how Klarissa and Luna already created the first edges and wanted to make sure that they were sufficient in number by counting the edges in the program. Both were satisfied when they created 12 edges (Fig. 11).

\section{Analysis Aspect 1: Domains of Subjective Experience}

First, it was striking but expected that the context specificity of mathematical knowledge regarding the DSE concept aligned with the actions and language the students

Table 2 Transcript excerpt I from the construction phase

67 Klarissa: \#00:04:22-1\# How many do we have now? (taps with her finger on the screen)

68 Luna: \#00:04:33-0\# Two, four, six

69 Klarissa: \#00:04:39-8\# There are missing one ... two (view on the screen, see Fig. 9). We need ... we've got eight (points on the screen)

70 Luna: \#00:04:48-4\# We still need the edges ...these (taps with her finger on the screen) are the corners 


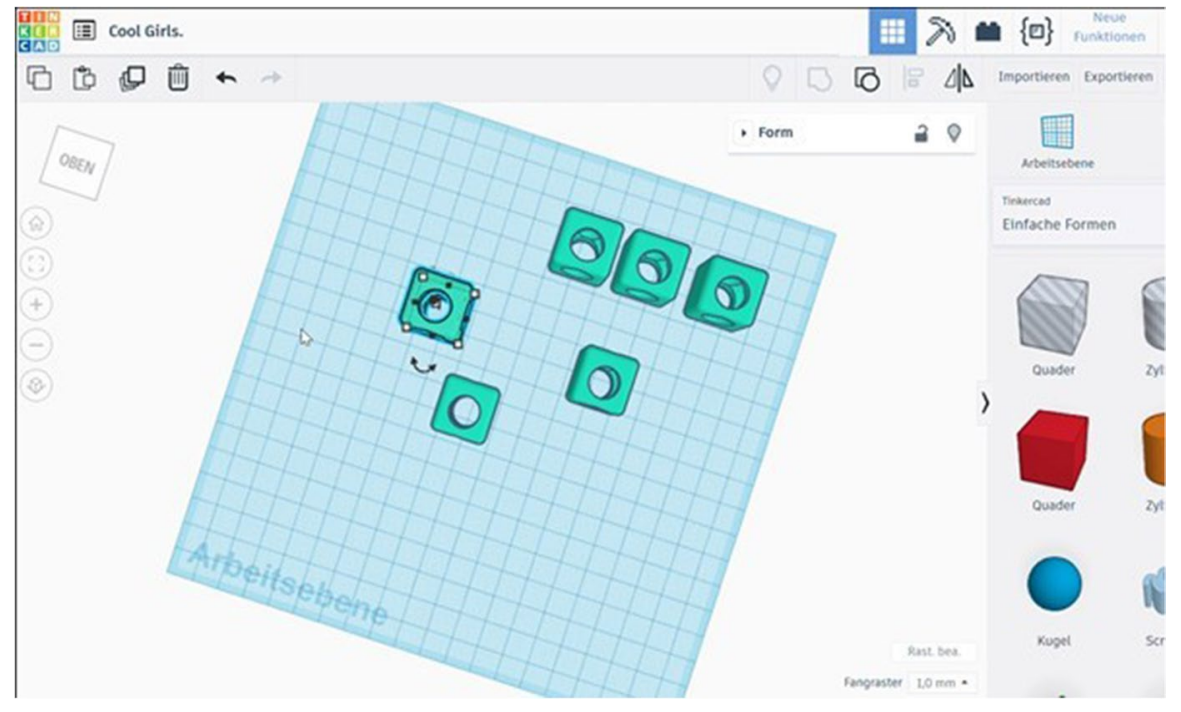

Fig. 9 View on six constructed corners in the interface of the program

used during their work on geometrical objects in the described learning environment. The students acted on geometrical objects in connection to specific empirical contexts. ${ }^{3}$ We propose a definition of each context as follows.

Context: 3D Printing In the context of 3D printing, objects that characterize this DSE are (geometric) objects made of plastic. They can be used to carry out a wide range of actions, such as a student plugging them into another matching solid or assembling stable objects and specific models of solids, which can be placed anywhere, rotated, held, and more.

Context: Tinkercad The context of the CAD program Tinkercad comprises virtually available geometric objects and operations of the program (scale, drill, reduce, group, and others; see also Figs. 1, 2, 3, and 4).

Context: Geometric Objects In the context of geometric objects, the students used the term "solid" or names of specific solids and associated terms of properties (such as "corner," "edge," and "side") that occurred in acts of drawing or writing.

To illustrate the matching of the students' actions and language to the specific contexts, we refer to the data in the initial part of this section. In the first transcript, the students discussed "twelve sticks" (Table 1, turn 261) and "eight little cubes" (Table 1, turn 263), which indicates the (DSE) context geometric objects (Fig. 6)

\footnotetext{
${ }^{3}$ By empirical contexts, we mean that, in mathematics classes, mathematical knowledge is usually developed in empirical contexts, especially drawings and application frameworks (Dilling \& Witzke, 2020a). Subsequently, teaching mathematics at school often involves an empirical belief system shaped by material and illustrations.
} 
and 3D printing, which includes 3D-printed objects (Fig. 8). These terms, "sticks" and "little cubes," are typical for the context of 3D printing technology, and this DSE has a specific language use (Tiedemann, 2016). "According to Bauersfeld (1988, p. 178), the subjective realization of a mathematical object remains always bound to the context of experience, i.e., to the objects and language used in the situation of construction" (Fetzer \& Tiedemann, 2018, p. 1288).

Klarissa thought about what she would like to call the geometric objects created by the 3D printing technology. She described the cylinders developed with the aid of 3D printing technology as "sticks" and the cubes created by the technology as corners of the model with "little cubes" (Fig. 8 and Table 1). The knowledge development of the two students is a domain-specific process bound to a specific context, which becomes noticeably clear when examining the terms they use. In the following sentence, Luna made it clear (supported by a gesture) that it was of major importance to her that the action of putting the empirical objects "sticks" and "little cubes" together requires precision: "Ehm ... and the sticks must be designed to fit exactly into the little cubes" (Table 1, turn 265). They realized that the sticks must fit into the little cubes, because, once they have been printed, hardly any adjustments to the pieces can be made.

Notably, the students later changed the terms they used for the pieces of their kit with the new virtual context of the CAD program that we describe as the Tinkercad DSE (Table 2). Surprisingly, contrary to the first transcript (Table 1), Klarissa and Luna no longer spoke of "sticks" and "little cubes" (Table 1, turn 265) but of "corners" and "edges" (Table 2, turn 70), more general terms related to the properties of the cube. Luna stated, "We still need the edges. These (tapping with her finger on the screen) are the corners" (Table 2, turn 70).

This change is striking, given that the virtual setting of Tinkercad provides the students with a realistic projection of the 3D-printed empirical pieces of the edge model kit. We expected the students to discuss "sticks" and how to fit them into the "little cubes." However, it seems that the new context (at least, examining the terms used) led to the activation of a more general DSE, the one provided at the beginning of the lesson in the whole classroom session when emphasizing the short profile of the cube (Fig. 7). Hypothetically, students might use the more general terms "corners" and "edges" as they realize that the given analog and virtual contexts share similarities but are nonetheless not the same. However, what obviously connects them is the general characteristics of the edge models, namely, consisting of eight corners and twelve edges (Fig. 7).

Table 3 Transcript excerpt II from the construction phase

\begin{tabular}{|c|c|c|c|}
\hline 102 & Klarissa: & \#00:10:12-4\# & We've got eight corners finished. How do we create the edges? \\
\hline 103 & Luna: & \#00:10:14-2\# & $\begin{array}{l}\text { They have to fit in there. How do we get them to fit in there? } \\
\text { (takes a cylinder from the edge bar and holds it exactly over } \\
\text { a drilled recess from an already created cornerstone on the } \\
\text { workplane; see Fig. 10) }\end{array}$ \\
\hline
\end{tabular}

121 Teacher: \#00:14:11-3\# Ask yourself, which property of the two objects must be equal to fit perfectly? You can also use the ruler of the program 


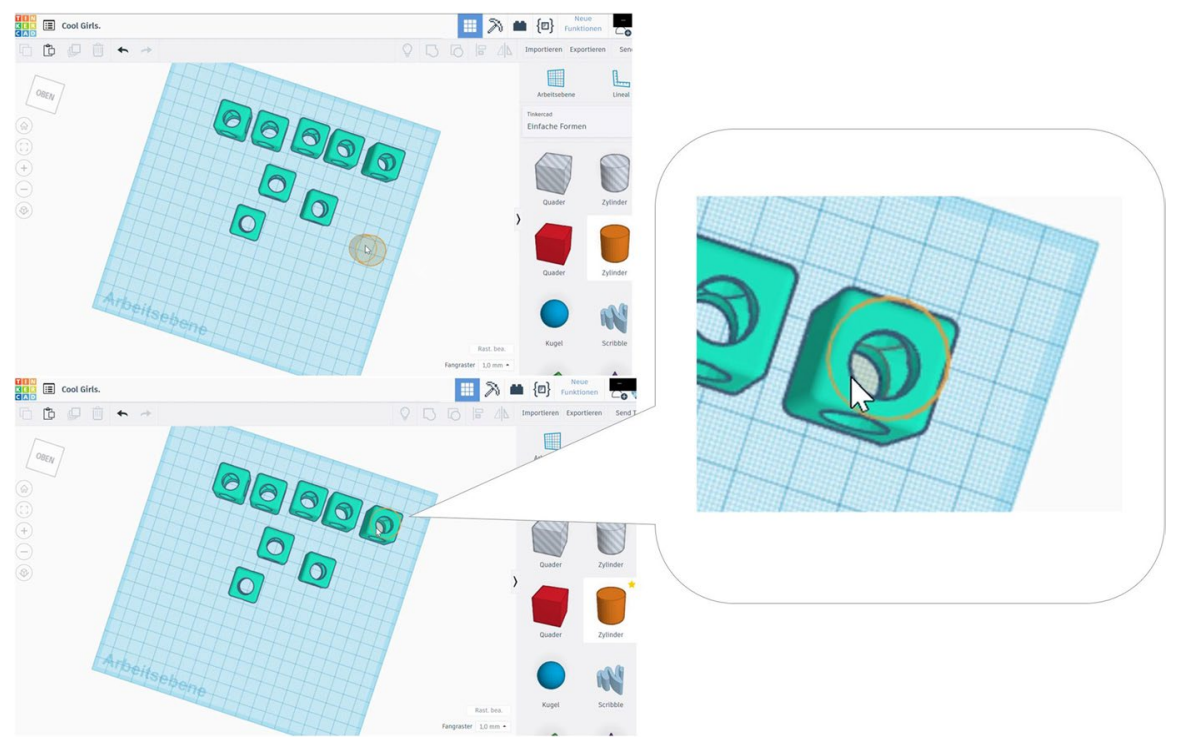

Fig. 10 Screenshots of the students' actions in the program for precise creation of edges

More precisely, the objects and actions that can be performed on and with them in the new context of the Tinkercad DSE differ from the objects and related actions in the 3D printing one. The former is about virtual objects that can be processed virtually. For example, the objects can be moved on the work plane in the program's interface, the dimensions can be adjusted, objects can be zoomed in and the virtual projections of objects can be pushed into one another (Figs. 1 and 10). There is a clear difference from the 3D printing DSE, where it is a matter of "solid" geometric objects that can be touched and physically experienced and must fit into one another.

The transcript excerpt in Table 3 indicates that, while working in the new context (DSE) Tinkercad, Klarissa and Luna still thought about how to put their virtual design into the $3 \mathrm{D}$ print practice, as indicated by the work assignment. The students were busy ensuring that the edges in form of cylinders would eventually fit into the recess of the cube comprising the corners (Figs. 8 and 10). This property must be considered, especially in the context of 3D printing technology (already included in the first transcript, Table 1).

\section{Analysis Aspect 2: The Toulmin model}

When implementing the new context (DSE) Tinkercad and using this software in an elementary school, we expected that the students would make full use of the software's possibilities, especially the opportunity to measure and set lengths with the convenient dimension function, which is always present when working with figures in the work plane (see Fig. 12): 


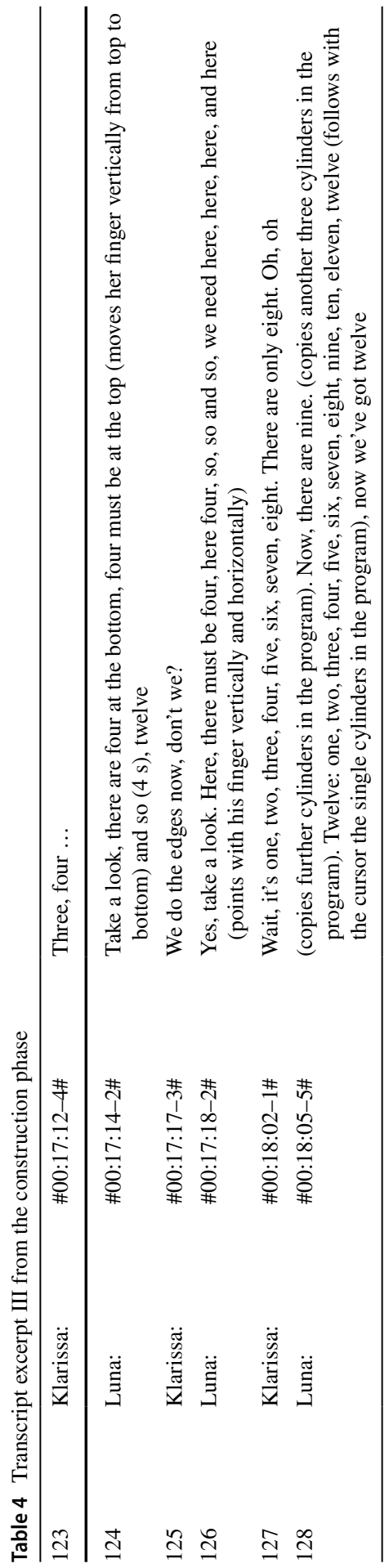




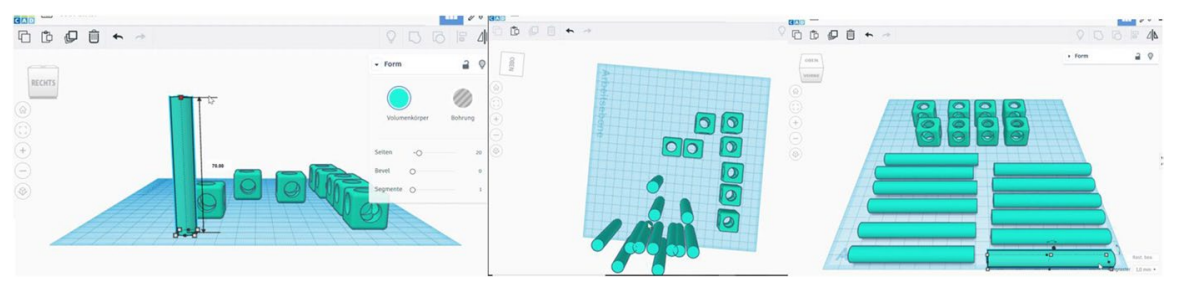

Fig. 11 Construction and creation of further edges in Tinkercad

- when clicking on objects, the program always displays the dimensions in millimeters;

- by changing the displayed number, one can immediately adjust the dimensions;

- with the ruler function, it is easy to measure constructed objects precisely.

We expected the students to use measuring (following the standards and the teacher's report), which they had already developed in the analog world, in the CAD program, the virtual world. As stated in the German standards, it was assumed that the students could convert measured data from a larger unit to a smaller one. The focus in the described learning setting was on the intuitive understanding that geometric figures (in this case, cubes) can be analyzed and classified based on their properties, such as parallel sides, perpendicular sides, particular angle measures, and symmetry.

With the new Tinkercad context, which suggestively addresses measurement activities in our understanding, we assumed that both the students' knowledge and their abilities in the field of measurement would be used to create the edge models. Surprisingly, the students did not apply their knowledge in measurement in this new context. More precisely, it was striking to see that the fourth-graders, who were quite familiar with measuring based on standard units (indirect comparison), did not activate this knowledge in the Tinkercad DSE. To describe this finding in detail,

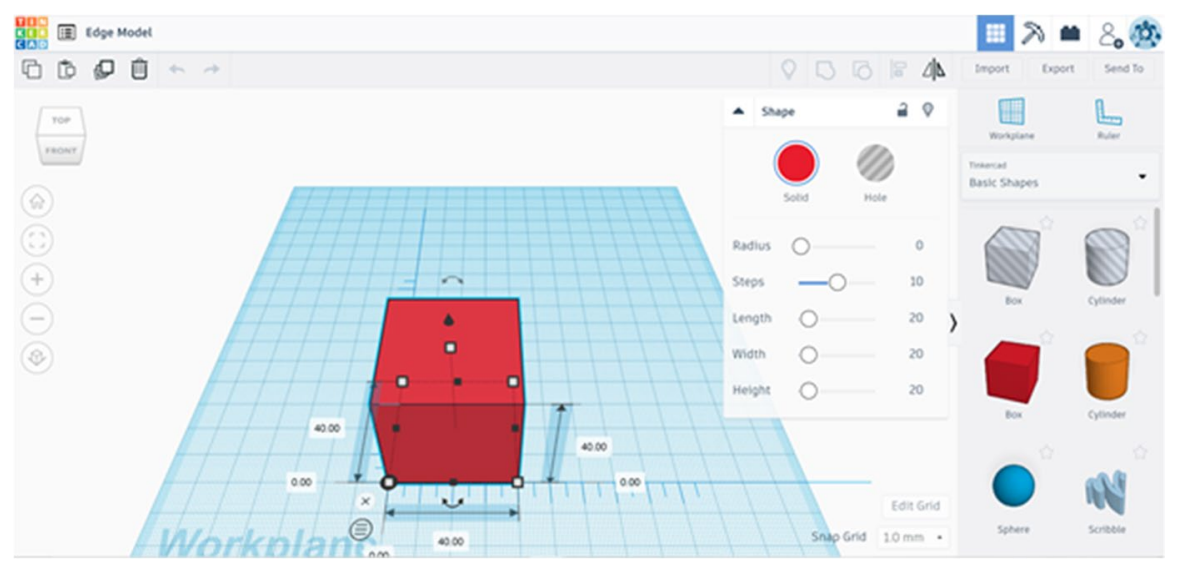

Fig. 12 Tinkercad and the opportunity to measure 
we use the Toulmin model because it provides an analytical tool to display what students base their arguments on in a new unfamiliar (virtual) context as it was provided with the CAD environment.

Examining the transcripts, from the viewpoint of the measuring processes, it was interesting when Klarissa and Luna explained that the "sticks" have to fit into the "little cubes" in the whole classroom session (Table 1, turn 265). These students noticed this aspect at the beginning of the learning unit, and it was also important to them when working with the program, which becomes clear from the following student quotation: "They have to fit in there. How do we get them to fit in there?" (Table 3, turn 103). Table 3 and the actions (Fig. 10) of the two students (takes a cylinder from the edge bar and holds it exactly over a drilled recess from an already created cornerstone on the work plane) indicate that the students activated estimation procedures in the Tinkercad DSE, rather than measurement procedures, when justifying that the "sticks" fit into the "little cubes."

In Table 3, turn 103, Luna made it clear through words and gestures that fitting the "sticks" into the "little cubes" was a major issue for her regarding the design of the edge model. She stated, "They have to fit in there. How do we get them to fit in there?" It is interesting that Luna took the cylinder from the edge bar and held it exactly over a drilled recess from an already created cornerstone on the work plane of the program. The observed accuracy when placing the two objects on top of each other was of particular interest to her. In Fig. 13, we describe this reasoning process using the Toulmin model.

As a thesis (conclusion), we set the students' desire to design a complete edge model kit for the cube, as this was the task of the day, and our observation indicates that they were quite aware of this task. However, how did they proceed to reach this conclusion? The short answer is solely by estimating dimensions, not by measuring them (Fig. 10). As depicted in Fig. 13, the argument (data) that the edges fit into the recess of the cubes used as corners in the edge model is because they did not see a precise measurement using the Tinkercad dimension function. As his Axiom 4, Schoenfeld (1985) wrote, "Hypothesis verification is purely empirical. Constructions are tested by implementing them. A construction is correct if and only if performing it provides the desired result (within some tolerance set by the individual)" (p. 161). In this sense, both the warrant and backing are based entirely on a purely empirical visual estimation in a virtual setting, working with (virtual) empirical objects.

They justify the fit by holding the cylinder with the mouse cursor exactly over the cube (Fig. 10), purely estimating the fitting of two (virtual) empirical objects. Examining the "geometrical measurement learning progression," the students interacted with this work on Level 1 only: "Intuitive/holistic/visual comparison. The student compares size as a whole or counts parts of an object at the holistic level but with no iteration of measurement units" (Kim et al., 2017, p. 6). A possible explanation for this result could be that the new and challenging (virtual) context (DSE) Tinkercad seemed too much to handle, so that the students went back to a stable but rather inadequate procedure of guessing visually.

Furthermore, this first reasoning process reminds us of the pure empiricist Schoenfeld (1985) described in his studies. With the help of axioms, he described the archetype of such a pure empiricist. Three of these axioms (Axiom 1, 4, and 5) seem 


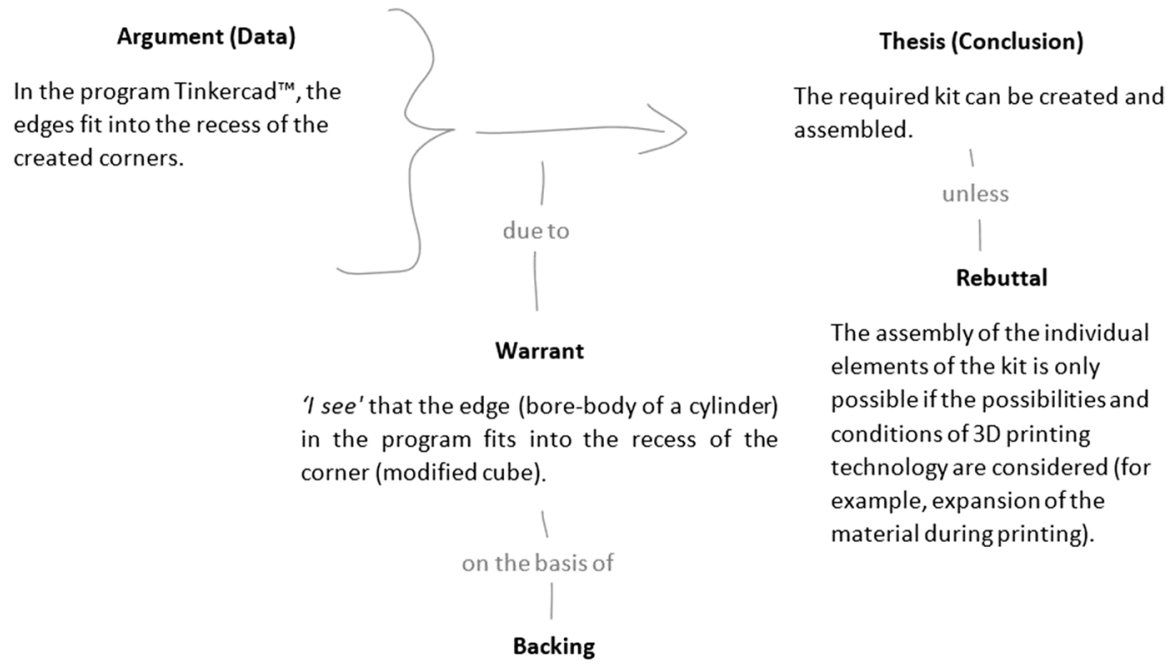

\begin{abstract}
Regardless of the program view (top, bottom, front, back, left, right) there are no visible gaps between the edge and the recess in the corner in the program. This means: different perspectives confirm the visual (subjective) impression of the fitting ('lt looks like it fits').
\end{abstract}

Fig. 13 Reasoning process I

the most important. As described in Axiom 1, students initially judge their results in the program solely on how it looks. In our case, it was not a drawing but a projection in the interface of the Tinkercad program. According to Axiom 4, students judge the accuracy of the fit in the program by whether the desired result can be delivered (i.e., whether or not the edge (cylinder) fits into the recess of the corner (cube)), which can be tested by pushing the edge into the recess of the corner in the program. In the sense of Axiom 5, the students do not need to make conclusive connections (e.g., a comparison of the dimensions or diameters). Thus, we can describe the first reasoning process (Fig. 13) as a purely empirical procedure.

How can a more adequate mathematical handling of these empirical objects be stimulated? How can we motivate students to activate their knowledge of measuring? In our example, the strong (suggestive) advice of the teacher played a decisive role for Klarissa and Luna (Table 3, turn 121): "Ask yourself, which property of the two objects must be equal to fit perfectly? You can also use the ruler of the program." This suggestion proved decisive for Klarissa and Luna to act mathematically adequately and to develop their knowledge further. Using the Toulmin model, this process can be described as follows in Fig. 14.

We describe the data, conclusion, and rebuttal for the second reasoning process (Fig. 14) in the same way as in the first reasoning process (Fig. 13). However, warrant and backing are different in this case, due to the teacher's (suggestive) advice on the measurement of the recesses, the ruler in the program, and the limitations of the printing realizations. The data (In the program Tinkercad, the edges fit into the 


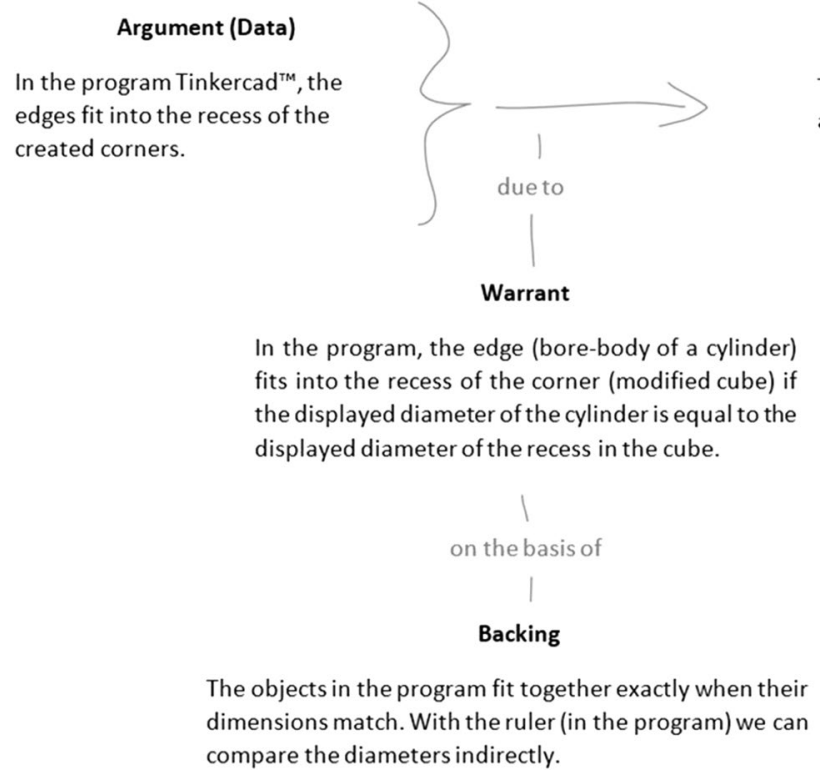

Argument (Data)

In the program Tinkercad ${ }^{\mathrm{T} m}$, the edges fit into the recess of the created corners.
Thesis (Conclusion)

The required kit can be created and assembled.

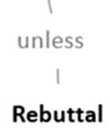

The assembly of the individual elements of the kit is only possible if the possibilities and conditions of $3 \mathrm{D}$ printing technology are considered (for example, expansion of the material during printing).

Fig. 14 Reasoning process II

recess of the created corners) can be described as being supported by the following different warrant: "In the program, the edge fits into the recess of the corner if the displayed diameter of the cylinder is equal to the displayed diameter of the recess in the cube." This warrant is reinforced by the empirical fact that objects fit together in the analog world only when their dimensions match. This fact can be tested precisely only by using the ruler in Tinkercad (backing). ${ }^{4}$

Using the work by Kim and colleagues (2017), we classified the second reasoning process at their Level 4: "Interval-scale concept related to the use of efficient composite units (formalization stage). The student measures with an efficient composite unit for each dimension and visualizes its spatial structure." (p. 7) For the lengths, we classified the process at Level 5: "General model (abstraction stage). The student operates in the abstract regarding the concepts of measurement." (p. 7) The students used the same conclusive connection that the objects fit into each other when their dimensions match, but this was due to a precise dimension specification using the functions of Tinkercad, e.g., the ruler in the program (cf. warrant and backing in Fig. 14). In other words, the conclusive connection, in this case, is as follows: In the program, the edge (bore-solid of a cylinder) fits into the recess of the corner (modified cube) if the displayed diameter of the cylinder is equal to the displayed diameter of the recess in the cube. Thus, the students activate procedural geometric knowledge initiated by the teacher and rely on knowledge that is beyond the program.

\footnotetext{
${ }^{4}$ In the context (DSE) Tinkercad, it was so that the (virtual) geometric objects could also be pushed into one another-the domain specificity of knowledge.
} 


\section{Conclusion}

In this summary, we revisit our research questions:

RQ 1: What influence does the CAD software Tinkercad have on student reasoning processes in mathematical learning settings?

RQ 2: What are the characteristics of the implementation of this new context in mathematics classes?

Related to RQ 1, our contribution demonstrates the influence that a new (virtual) context, such as the CAD software Tinkercad, can have on the mathematical learning processes of elementary school students. The virtual and physical contexts (DSEs) may appear similar at first; however, clear differences exist that influence the behavior and decisions of the students. The physical and mental actions involved in manipulating solid and unchangeable objects in the geometric objects DSE and 3D printing DSE appear to differ from those in the Tinkercad DSE's virtual objects (projections).

Regarding RQ 2, the DSEs provide an appropriate descriptive framework to examine the characteristics of the individual student reasoning processes in the newly introduced context. Although we expected that the students would continue to refer to "sticks" and how to move them into the "little cubes," the children's language changed in the Tinkercad DSE, suggesting that the virtual environment activates a more general DSE (the short profile of the cube, Fig. 7) and more general use of terms. The teacher's (suggestive) advice can be interpreted as an occasion for the students to measure in the new context (DSE) Tinkercad.

The result of this advice was that the students activated procedural geometric knowledge that goes beyond the knowledge required for the program. Therefore, the teacher is important in facilitating the students to reach Levels 4 and 5 (Kim et al., 2017), namely, the knowledge that the created edge (a bore-solid of a cylinder in the program) must fit into the circular recess of the corner (a modified cube in the program). It does fit if the displayed diameter of the cylinder is equal to the displayed diameter of the recess in the cube. The students relied on specific knowledge about dimensions, measurement processes, and efficient units to measure. In terms of Schoenfeld (1985), the teacher's advice, "Ask yourself, which property of the two objects must be equal to fit perfectly? You can also use the ruler of the program" (Table 3, turn 121) helped them to move beyond pure empiricism.

The new context, in this case, challenges the student reasoning process in a mathematical learning setting concerning geometric solids. Thus, it is not enough to introduce a digital medium, such as Tinkercad, into the classroom. It takes the teacher to make it meaningful, which remains interesting for further studies in mathematics education. What guiding advice can (or must) a teacher offer to preserve a focus on mathematics when lessons involve digital media? How must the teacher's advice be designed so that students develop (mathematical) reasoning processes, especially when dealing with digital media in the classroom? Because this study is about a specific case, it would be beneficial to examine some issues more broadly. 
Thus, the authors are also interested in the extent to which teachers can initiate (mathematical) reasoning processes in students through digital media, so that students leave behind the status of a pure empiricist or do not even develop it.

Funding Open Access funding enabled and organized by Projekt DEAL.

\section{Declarations}

Competing Interests The authors declare no competing interests.

Open Access This article is licensed under a Creative Commons Attribution 4.0 International License, which permits use, sharing, adaptation, distribution and reproduction in any medium or format, as long as you give appropriate credit to the original author(s) and the source, provide a link to the Creative Commons licence, and indicate if changes were made. The images or other third party material in this article are included in the article's Creative Commons licence, unless indicated otherwise in a credit line to the material. If material is not included in the article's Creative Commons licence and your intended use is not permitted by statutory regulation or exceeds the permitted use, you will need to obtain permission directly from the copyright holder. To view a copy of this licence, visit http://creativecommons.org/licen ses/by/4.0/.

\section{References}

Autodesk (2020). From mind to design in minutes [Homepage]. (https://www.tinkercad.com/)

Bauersfeld, H. (1983). Subjektive Erfahrungsbereiche als Grundlage einer Interaktionstheorie des Mathematiklernens und -lehrens. In H. Bauersfeld, H. Bussmann, \& G. Krummheuer (Eds.), Lernen und Lehren von Mathematik: Analysen zum Unterrichtshandeln II (pp. 1-57). Aulis-Verlag Deubner.

Bauersfeld, H. (1988). Interaction, construction, and knowledge: Alternative perspectives for mathematics education. In D. Grouws \& T. Cooney (Eds.), Perspectives on research on effective mathematics teaching (pp. 27-46). Lawrence Erlbaum Associates.

Bauersfeld, H. (2000). RadikalerKonstruktivismus, Interaktionismus und Mathematikunterricht. In E. Begemann (Ed.), Lernen verstehen - Verstehen lernen (pp. 117-145). Peter Lang.

Bruner, S. (1974). Toward a theory of instruction. Harvard University Press.

Dilling, F., \& Vogler, A. (2021). Fostering spatial ability through computer-aided design: A case study. Digital Experiences in Mathematics Education, 7(2), 323-336. https://doi.org/10.1007/ s40571-021-00084-w

Dilling, F., \& Witzke, I. (2020a). The use of 3D-printing technology in calculus education: Concept formation processes of the concept of derivative with printed graphs of functions. Digital Experiences in Mathematics Education, 6(3), 320-339.

Dilling, F., \& Witzke, I. (2020b). Comparing digital and classical approaches: The case of tessellation in primary school. In B. Barzel, R. Bebernik, L. Göbel, M. Pohl, H. Ruchniewicz, F. Schacht \& D. Thurm (Eds), Proceedings of the 14th International Conference on Technology in Mathematics Teaching (pp. 83-90). University of Duisburg-Essen.

Fetzer, M., \& Tiedemann, K. (2018). Talking with objects. In T. Dooley \& G. Gueudet (Eds), Proceedings of the Tenth Congress of the European Society for Research in Mathematics Education (pp. 1284-1291). Dublin City University and ERME.

Gibson, I., Rosen, D., \& Stucker, B. (2014). Additive manufacturing technologies: 3D printing, rapid prototyping, and direct digital manufacturing. Springer.

Hartmann, W., Näf, M., \& Reichert, R. (2007). Informatikunterricht planen und durchführen. Springer.

Kim, E., Haberstroh, J., Peters, S., Howell, H., \& Oláh, L. (2017). A learning progression for geometric measurement in one, two, and three dimensions (Research Report No. RR-17-55). Educational Testing Service. 
KMK (2005). Beschlüsse der Kultusministerkonferenz vom 15.10.2004: Bildungsstandards im Fach Mathematik für den Primarbereich. Wolters Kluwer Deutschland GmbH.

Krummheuer, G. (2003). Argumentationsanalyse in der mathematikdidaktischen Unterrichtsforschung. ZDM: The International Journal on Mathematics Education, 35(6), 247-256.

Lehrplan NRW (2008). Lehrplan Mathematik Grundschule.(https://www.schulentwicklung.nrw.de/lehrp laene/upload/klp_gs/LP_GS_2008.pdf)

Loui, R. (2006). A citation-based reflection on Toulmin and argument. In D. Hitchcock \& B. Verheij (Eds.), Arguing on the Toulmin model: New essays in argument analysis and evaluation (pp. 31-38). Springer.

Meyer, M. (2010). Wörter und ihr Gebrauch: Analyse von Begriffsbildungsprozessen im Mathematikunterricht. In G. Kadunz (Ed.), Sprache und Zeichen (pp. 49-82). Franzbecker.

$\mathrm{Ng}$, O.-L. (2017). Exploring the use of 3D computer-aided design and 3D printing for STEAM learning in mathematics. Digital Experiences in Mathematics Education, 3(3), 257-263.

Ng, O.-L., \& Sinclair, N. (2018). Drawing in space: Doing mathematics with 3D pens. In L. Ball, P. Drijvers, S. Ladel, H.-S. Siller, M. Tabach, \& C. Vale (Eds.), Uses of technology in primary and secondary mathematics education: Tools, topics and trends (pp. 301-313). Springer.

Ng, O.-L., Sinclair, N., \& Davis, B. (2018). Drawing off the page: How new 3D technologies provide insight into cognitive and pedagogical assumptions about mathematics. The Mathematics Enthusiast, 15(3), 563-578.

Pielsticker, F. (2020). Mathematische Wissensentwicklungsprozesse von Schülerinnen und Schülern: Fallstudien zu empirisch-orientiertem Mathematikunterricht mit 3D-Druck. Springer.

Pielsticker, F. (2021). Concept formation processes regarding height and base in triangles. International Electronic Journal of Mathematics Education, 16(2), (10). https://doi.org/10.29333/iejme/108910

Pielsticker, F., \& Witzke, I. (2022). Entwicklung mathematischen Wissens in empirischen Kontexten. Mathematica Didactica, 45(1), (19). (http://www.mathematica-didactica.com/Pub/md_2021/ md2021_Pielsticker_Witzke_Modellierung.pdf)

Puentedura, R. (2013). SAMR: Moving from enhancement to transformation. Workshop at the 2013 AIS ICT Management and Leadership Conference, Canberra, Australia.(http://www.hippasus.com/rrpwe blog/archives/000095.html)

Schoenfeld, A. (1985). Mathematical problem solving. Academic Press.

Tiedemann, K. (2016). "Ich habe mir einfach die Rechenmaschine in meinem Kopf gebaut!" Zur Entwicklung fachsprachlicher Fähigkeiten bei Grundschulkindern. Beiträge zum Mathematikunterricht 2016 (pp. 991-994). WTM-Verlag.

Toulmin, S. (1958/1996). Der Gebrauch von Argumenten (2nd edn; trans. U. Berk). Beltz.

Publisher's Note Springer Nature remains neutral with regard to jurisdictional claims in published maps and institutional affiliations. 